\title{
UM ESTUDO FENOMENOLÓGICO SOBRE A VIVÊNCIA DE FAMÍLIA: COM A PALAVRA, A COMUNIDADE
}

O objetivo desta pesquisa foi investigar a vivência de família a partir da perspectiva de pessoas moradoras do Conjunto Santa Maria, comunidade popular da cidade de Belo Horizonte (MG). Foram entrevistadas três pessoas, e se utilizou, na análise dos depoimentos, o método fenomenológico de pesquisa. Esta permitiu a apreensão dos elementos essenciais do viver em família, apresentados sob a forma de unidades de sentido, agrupadas nos seguintes temas representativos: 1) a concepção de família: definição, configuração familiar, posturas na família e elementos estruturantes; 2) os papéis na dinâmica familiar; 3) elementos desestruturantes da família; 4) os problemas enfrentados pela família; 5) a percepção das famílias da comunidade; e, 6) a vivência do trabalho com as famílias da comunidade. Como conclusão, foi enfatizado o mérito do estudo da vivência da família para o desenvolvimento de projetos e programas de assistência comunitária e para as possíveis contribuições do psicólogo na assistência à comunidade.

\section{BANCA:}

Terezinha Féres-Carneiro (Orientadora)

Bernardo Jablonski

Edna Lúcia Tinoco Ponciano

José Paulo Giovanetti

Teresinha Mello da Silveira

Data de defesa: 03/12/2007 